\title{
CAPACITAÇÃO PROFISSIONAL DOS DOCENTES EM RELAÇÃO AOS ALUNOS COM NECESSIDADES ESPECIAIS
}

http://dx.doi.org/10.5902/2176217110906

\author{
Aline Augusti Boligon \\ Universidade Federal de Santa Maria, Brasil. \\ Leticia Pinton \\ Universidade Federal de Santa Maria, Brasil. \\ Francieli Sanches \\ Universidade Federal de Santa Maria, Brasil. \\ Fabiane Romano de Souza Bridi \\ Universidade Federal de Santa Maria, Brasil.
}

\begin{abstract}
Resumo
Este trabalho tem como objetivo identificar quais são as principais necessidades dos docentes do ensino técnico profissionalizante e superior em relação à inclusão de alunos com necessidades educacionais especiais na rede regular de ensino. Foi realizado um questionário misto com vinte professores do ensino técnico profissionalizante e superior da cidade de Santa Maria, RS. Após a transcrição dos relatos, fez-se uma leitura ampla do material obtido. Em seguida, os dados referentes às questões abertas e fechadas, foram codificados, tabulados e analisados em porcentagem. Os resultados demonstraram que todos os professores defendem a necessidade de formação continuada para a educação inclusiva. Os docentes citaram a falta de apoio estrutural, especializado e formativo nas instituições, além disso, faz-se necessário a implantação de políticas públicas e planejamento educativo inclusivo.

Palavras-chave: educação inclusiva, formação continuada, políticas públicas.
\end{abstract}

\section{PROFESSIONAL TRAINING OF TEACHERS IN RELATION TO STUDENTS WITH SPECIAL NEEDS}

\section{Abstract}

This work aims to identify what are the main needs of teachers of technical education and vocational higher compared to the inclusion of students with special educational needs in 
mainstream education. We conducted a mixed questionnaire with twenty teachers of technical education and vocational upper town of Santa Maria, RS. After transcription of reports, made it a broad reading of the material obtained. Then the data on open and closed questions were coded, tabulated and analyzed in percentage. The results showed that all teachers support the need for continuing education for inclusive education. Teachers cited a lack of structural support, and training in specialized institutions, moreover, it is necessary to implement public policy and planning inclusive education.

Key-word: inclusive education, continuing education, public policies. 


\section{Introdução}

Nos últimos anos ocorreram avanços importantes em relação à formação de professores a nível mundial e nacional, não apenas em termos de legislação, mas também em relação à produção do conhecimento acadêmico voltado para o tema (Pletsch, 2009; Fartes; Gonçalves, 2009).

Pela Declaração de Salamanca (Unesco, 1994) foi instituído e disseminado o conceito de escola inclusiva, evidenciando uma preocupação com todas as pessoas que se encontram excluída da escola em função de etnia, gênero, classe social, necessidades educacionais especiais, entre outras. Os termos necessidades educacionais especiais e educação inclusiva referem-se à escolarização de alunos que apresentam deficiências sensoriais - visual e auditiva -, mental/intelectual, física, múltipla, transtornos globais do desenvolvimento - autismo, psicose e outros - e altas habilidades/superdotação, tal qual como previsto na Política nacional de educação especial na perspectiva da educação inclusiva (Brasil, 2008).

No Brasil, inúmeros documentos e diretrizes fazem referência aos direitos educacionais e sociais das pessoas com necessidades especiais, tomando como base filosófica os referenciais internacionais (Silva; Pletsch, 2010). Dentre estes destacamos a Lei de Diretrizes e Bases da Educação Nacional, a qual reserva um capítulo exclusivo à educação especial. O destaque recebido reafirma o direito à educação, pública e gratuita, das pessoas com necessidades especiais. Por esta legislação, a educação especial deve ser oferecida, preferencialmente, na rede regular de ensino, para educandos portadores de necessidades especiais. Nesse mesmo capítulo afirma-se que os sistemas de ensino assegurarão aos estudantes currículos, métodos, técnicas, recursos educativos e organização específicos para atender às suas necessidades. No entanto, não trata temas relevantes como a existência de outros elementos que podem interferir de forma significativa no processo de inclusão, como os equipamentos e materiais específicos e acessibilidade arquitetônica (Brasil, 1996; Rinaldi et al., 2007; Silva; Pletsch, 2010).

No que se refere à implementação da Política nacional da educação especial na perspectiva da educação inclusiva (Brasil, 2008), é importante dizer que a mesma faz parte das diretrizes do Plano de metas compromisso todos pela educação, decreto $n$. 6.094/2007, que pretende garantir o acesso e a permanência no ensino regular e o atendimento às necessidades educacionais especiais dos alunos, fortalecendo seu ingresso nas escolas públicas por meio da implantação de salas de recursos multifuncionais, a acessibilidade arquitetônica dos prédios escolares, acesso e a permanência na educação superior, entre outras medidas. Tais aspectos são reforçados pelas Diretrizes operacionais para o atendimento educacional especializado na educação básica, modalidade educação especial (Brasil, 2009).

Educar um aluno com deficiência em um curso profissional é desafiador, instigador, especialmente pelo fato de que a sociedade, muitas vezes, já o rotulam como ineficaz ou doente, e, assim, considera-os inaptos para o ensino. Vencer essa barreira é algo que só um docente comprometido com a mudança e capacitado pode fazer. Muitas vezes, 0 docente não cria possibilidades diferenciadas para ensinar o conteúdo ou para que o aluno com deficiência avance no conhecimento, pois prefere usar o rótulo da incapacidade. É fundamental que o docente que atua na educação profissional inclusiva 
possua conhecimentos sobre interação social e saiba lidar com as diferenças, seja um docente que valorize a diversidade e seja responsável por dar crédito às potencialidades e não somente às dificuldades apresentadas pelo aluno. $O$ importante é entender o papel de cada ator envolvido na comunidade escolar; entender que o aluno é o aprendiz, indivíduo único, compreendido e valorizado como tal e que através da mediação com o outro, que poderá ou não ser o professor, com o meio, e a partir das condições oportunizadas, poderá construir seu conhecimento (Manica, 2011).

Ainda sobre a formação de professores, tanto inicial quanto continuada, cabe mencionar que a mesma tem sido apontada como elemento fundamental para a implementação das políticas de inclusão escolar (Bueno, 1999; Fontes, 2007; Glat; Pletsch, 2004). Apesar do avanço nas políticas públicas pró-direitos educacionais e sociais de pessoas com necessidades educacionais, as escolas enfrentam inúmeros problemas, tensões e contradições. Para discutir a implantação da política de inclusão escolar apresentamos uma pesquisa exploratória qualitativa sobre quais as principais necessidades dos docentes do ensino técnico profissionalizante e superior em relação à inclusão de alunos portadores de necessidades educacionais especiais na rede regular de ensino.

\section{Metodologia}

Para a realização dessa pesquisa foi utilizado um questionário misto com um roteiro de 14 questões que abordaram a identificação dos docentes: informações sobre idade, sexo, formação acadêmica, instituição, atuação profissional; as concepções sobre a educação inclusiva: opiniões dos profissionais acerca da inclusão de alunos com necessidades especiais no ensino regular; desenvolvimento do processo de inclusão: dificuldades encontradas pelos participantes na realização do processo; condições necessárias à efetivação da educação inclusiva: sugestões dos docentes quanto aos aspectos necessários para a viabilização da inclusão escolar.

A escolha dos professores baseou-se nos seguinte critério: os profissionais deveriam estar atuando em instituições de ensino público ou privado, realizando atividades com alunos de nível técnico profissionalizante, tecnólogo e superior.

Após a transcrição dos relatos, fez-se uma leitura ampla do material obtido. Em seguida, os dados foram codificados, tabulados e analisados em porcentagem.

\section{Resultados e discussão}

Dos docentes entrevistados treze $(65 \%)$ eram do sexo feminino e sete $(35 \%)$ do sexo masculino, sendo que a maioria dos docentes (nove) encontrava-se na faixa etária de 31 a 40 anos (figura 1). Quatro, (20\%) dos docentes, possuem a graduação, catorze (70\%) dos docentes possuem mestrado e dois (10\%) possuem o título de doutor (figura 2). Em relação à atuação profissional, dez docentes (50\%) atuam no ensino técnico, quatro $(20 \%)$ atuam no ensino tecnológico e seis $(30 \%)$ atuam no ensino superior (figura 3). Os docentes estavam vinculados a instituições públicas e privadas abertas à inclusão, que atendem alunos de diferentes cidades e Estados brasileiros. 
Figura 1

Número de docentes entrevistados com relação à faixa etária.

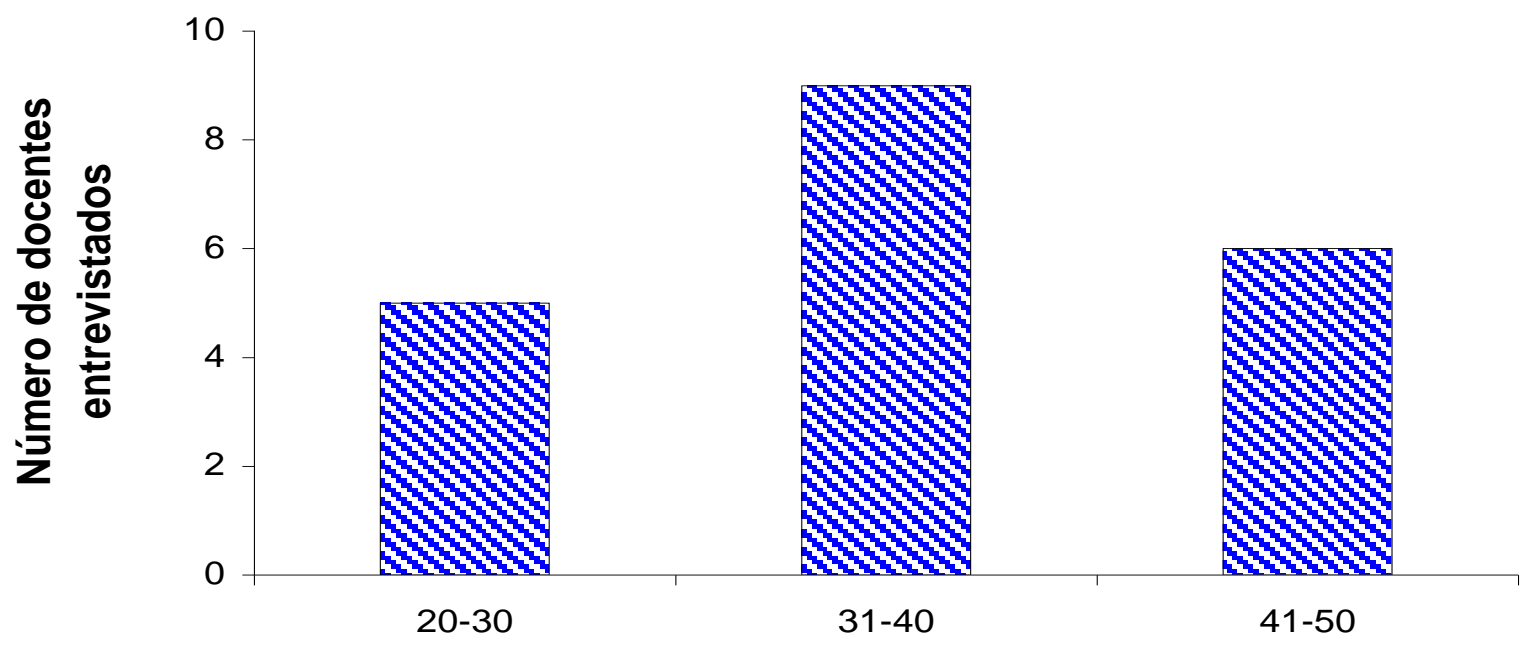

Faixa etária (anos)

Figura 2

Número de docentes entrevistados com relação ao grau de instrução.

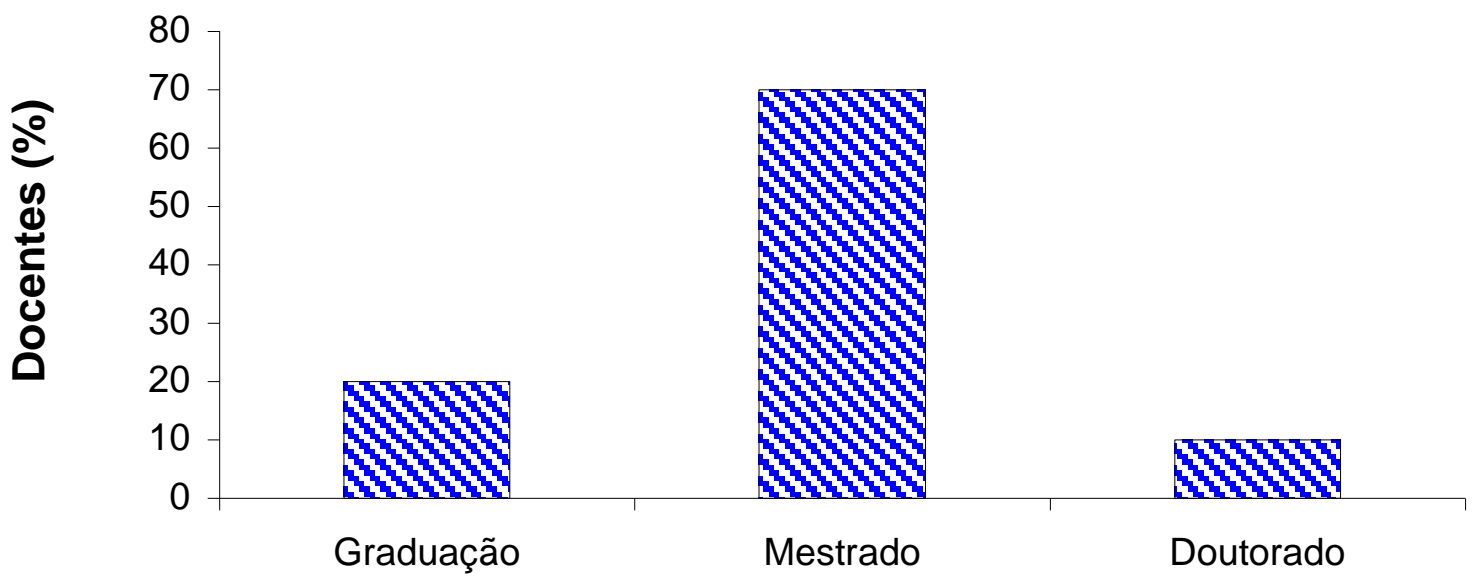

Titulação 
Figura 3

Número de docentes entrevistados com relação à atuação profissional.

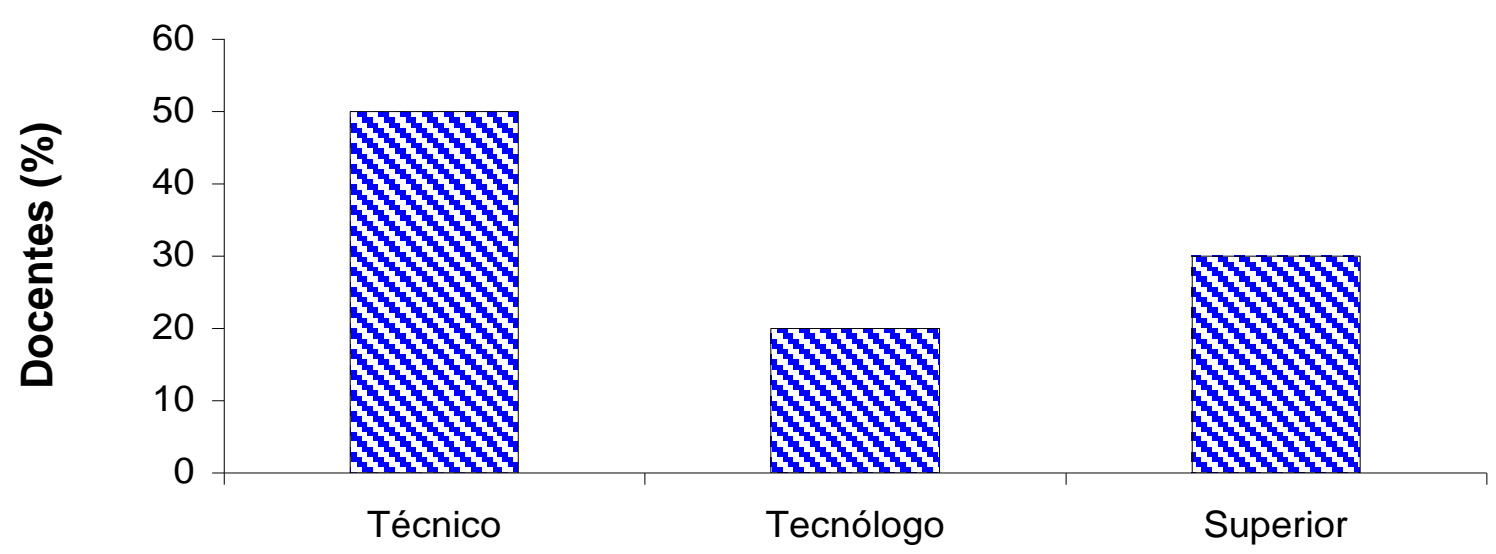

\section{Atuação profissional}

Ao perguntarmos sobre a inclusão de alunos portadores de necessidades especiais no ensino regular, podemos perceber, na figura 4 , que doze $(60 \%)$ docentes foram favoráveis e oito $(40 \%)$ foram desfavoráveis. Percebemos que a maioria dos docentes favoráveis à inclusão escolar pertence à faixa etária de 20-30 anos, o que pode ser justificado pela recente formação. Nas últimas décadas e, mais especificamente, a partir da Declaração de Salamanca, em 1994, a inclusão escolar de alunos com necessidades especiais no ensino regular tem sido tema de pesquisas e de eventos científicos, abordando-se desde os pressupostos teóricos político-filosóficos até formas de implantação das diretrizes estabelecidas na referida declaração (Sant'Ana, 2005). 
Figura 4

Número de docentes entrevistados com relação à inclusão de alunos com necessidades especiais em escolas regulares.

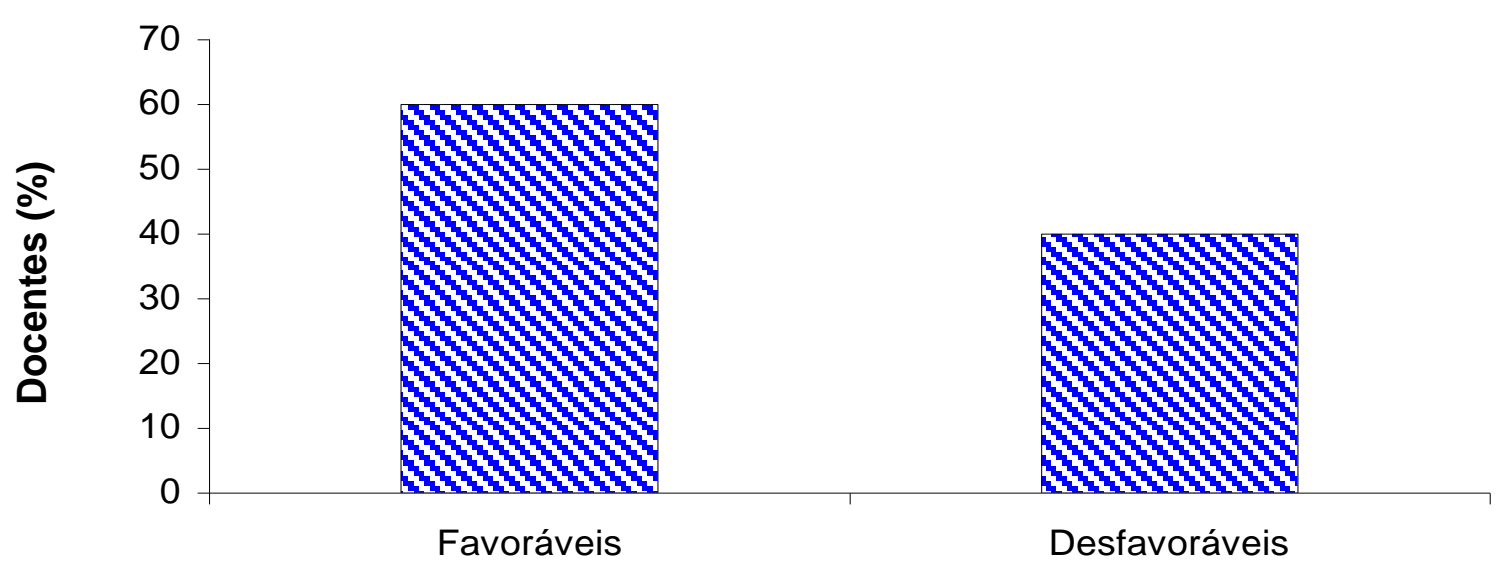

Inclusão de alunos com necessidades especiais

Ao serem questionados sobre ministrar aulas para alunos portadores de deficiência, a maioria dos entrevistados respondeu que não haviam se deparado com essa situação, além disso, nenhum dos docentes relata ter recebido capacitação necessária para trabalhar com alunos incluídos. Diagnóstico semelhante também foi traçado por Castro (2002), numa pesquisa realizada na rede municipal de educação de Santa Maria, RS, que analisou representações e sentimentos de professores diante da inclusão de alunos com necessidades especiais em suas salas de aula. Castro mostrou que os professores, de modo geral, não se sentem capacitados para receber um aluno com deficiência, apesar de acreditarem nos méritos da inclusão. Uma pesquisa realizada em âmbito nacional mostrou que os professores, de maneira geral, também não estavam preparados para receber em sua sala de aula alunos especiais (Glat et al., 2003).

Segundo Sant'Ana (2005), é importante que os professores sejam instrumentalizados, pela capacitação docente, a fim de atender às peculiaridades apresentadas pelos alunos. Para Gotti (1988), a universidade, além de proporcionar cursos de aperfeiçoamento e de pós-graduação, deve envolver pesquisas sobre o ensino aos portadores de necessidades especiais, desenvolvendo instrumentos e recursos que facilitem a vida dessas pessoas.

Em nosso estudo, os entrevistados destacaram que as políticas públicas de formação e capacitação docente não atendem a demanda da inclusão de alunos especiais e que é necessário haver mudanças para ocorrer a inclusão desses alunos nas instituições de ensino. Diversos estudos recentes têm reafirmado a necessidade da melhoria da formação de professores como condição essencial para a promoção eficaz da inclusão de alunos com necessidades especiais em rede regular de ensino (Bueno, 1999; Glat; Nogueira, 2002; 2003; Braun et al., 2003; Tonine; Costas, 2005; Glat et al., 2006; 
Pletsch; Fontes, 2006). Muitos professores reforçam a falta de capacitação para trabalhar com alunos com necessidades educacionais especiais (Silva; Pletsch, 2010).

Sobre esse aspecto Pletsch (2009) adverte que, num primeiro momento, são comuns sentimentos de incapacidade e até mesmo de medo frente ao ingresso de um aluno com algum tipo de deficiência ou distúrbio de comportamento em sala de aula regular. Em outras palavras, muitas vezes a falta de preparo e informação impede o professor de desenvolver uma prática pedagógica sensível às especificidades do aluno com necessidades educacionais especiais.

\section{Referências}

BRASIL. Lei de diretrizes e bases da educação nacional (lei n. 9.394/96). 20 de dezembro de 1996.

BRASIL. Política nacional de educação especial na perspectiva da educação inclusiva. Brasília, janeiro de 2008.

BRASIL. Diretrizes operacionais para o atendimento educacional especializado na educação básica, modalidade educação especial. Resolução no 4, de 2 de outubro de 2009.

BRAUN, Patrícia; PLETSCH, Márcia Denise. A formação inicial e continuada de recursos humanos para a prática docente frente à educação inclusiva. In: NUNES SOBRINHO, Francisco de Paula (org.). Inclusão educacional: pesquisa e interfaces. Rio de Janeiro: Livre Expressão, 2003, p. 98-149.

BUENO, José Geraldo Silveira. A educação inclusiva e as novas exigências para a formação de professores: algumas considerações. In: BICUDO, Maria Aparecida Viggiani; SILVA, Carlos Antônio Júnior (orgs.). Formação do educador e avaliação educacional: formação inicial e continuada. São Paulo: Unesp, 1999, p. 146-164.

CASTRO, Sabrina Fernandes. A representação social de professores de alunos incluídos em rede regular de ensino. Santa Maria: UFSM, 2002. Monografia (especialização em Educação Especial na área da Deficiência Mental). Universidade Federal de Santa Maria, Centro de Educação.

FARTES, Vera Bueno; GONÇALVES, Cássia Brandão. Formação de professores para a educação profissional de jovens e adultos no Brasil: novas relações com o saber, novo campo de trabalho na educação. Educação, Sociedade \& Culturas, v. 29, 2009, p. 109124.

GLAT, Rosana; FONTES, Rejane de Souza; PLETSCH, Márcia Denise. Uma breve reflexão sobre o papel da educação especial frente ao processo de inclusão de pessoas com necessidades educacionais especiais em rede regular de ensino. Cadernos de Educação 6: inclusão social desafios de uma educação cidadã, 2006, p. 13-30.

GLAT, Rosana; NOGUEIRA, Mário Lúcio de Lima. Políticas educacionais e a formação de professores para a educação inclusiva no Brasil. Revista Integração, v. 24, 2002, p. 22-27.

GLAT, Rosana; NOGUEIRA, Mário Lúcio de Lima. Políticas educacionais e a formação de professores para a educação inclusiva. Revista Comunicações, Piracicaba, v. 1, n. 1, 2003, p. 81-95.

GLAT, Rosana; PLETSCH, Márcia Denise. O papel da universidade frente às políticas públicas para educação inclusiva. Revista Benjamin Constant, v. 29, n. 1, 2004, p. 3-8. 
MANICA, Loni Elisete. A prática docente da educação profissional na perspectiva da inclusão. Revista Iberoamericana de Educación, n. 55/4, 2011, p. 1-9.

PLETSCH, Márcia Denise. A formação de professores para a educação inclusiva: legislação, diretrizes políticas e resultados de pesquisas. Educar, v. 33, 2009, p. 143-156.

PLETSCH, Márcia Dense; FONTES, Rejane de Souza. La inclusión escolar de alumnos con necesidades especiales: directrices, prácticas y resultados de la experiencia brasileña. In: Revista Educar: revista de Educación, n. 37, 2006, p. 87-97.

RINALDI, Renata Portela; REALI, Aline Maria Medeiros Rodrigues; COSTA, Maria da Piedade Resende. Educação especial e formação de professores: onde estamos... para onde vamos? Horizontes, v. 25, n. 1, 2007, p. 87-98.

SANT'ANA, Izabella Mendes. Educação inclusiva: concepções de professores e diretores. Psicologia em Estudo, v. 10, n. 2, 2005, p. 227-234.

SILVA, Isabelle Cristine Mendes; PLETSCH, Márcia Denise. A política de educação inclusiva no ensino técnico-profissional: resultados de um estudo de caso. Democratizar, v. 4, n. 1, 2010, p. 1-14.

TONINE, Andréa; COSTAS, Fabiane Adela Tonetto. Escola inclusiva: o desvelar de um espaço multifacetado. Revista Educação Especial, Santa Maria, n. 26, 2005. Disponível em: <www.ufsm,br/ce/revista>. Acesso em: 26 fev., 2006.

UNESCO. Declaração de Salamanca e linha de ação sobre necessidades educativas especiais. Brasília: Corde, 1994.

Aline Augusti Boligon é estudante do curso de doutorado em Ciências Farmacêuticas da Universidade Federal de Santa Maria.

Endereço: Avenida Roraima, n. 1000 - prédio 26 - sala 1411 - 97119-900 - Santa Maria - RS - Brasil.

E-mail: alineboligon@hotmail.com.

Leticia Pinton é estudante do curso de Estatística da Universidade Federal de Santa Maria.

Endereço: Avenida Roraima, n. 1000 - prédio 13 - 97119-900, Santa Maria, RS, Brasil.

E-mail: letpinton@hotmail.com.

Francieli Sanches é graduada em Administração.

Endereço: Rua Coronel Niederauer, 1783/209 - 97850-122 - Santa Maria - RS Brasil.

E-mail: fransanches@yahoo.com.br. 
Fabiane Romano de Souza Bridi é professora adjunta no Departamento de Educação Especial da Universidade Federal de Santa Maria.

Endereço: Avenida Roraima, 1000 - prédio 16 - 97105-900 - Santa Maria - RS Brasil.

E-mail: fabianebridi@gmail.com.

Recebido em 8 de outubro de 2013.

Aceito em 20 de outubro de 2013. 